\title{
On Mixed Flow Turbines for Automotive Turbocharger Applications
}

\author{
Bernhardt Lüddecke, Dietmar Filsinger, and Jan Ehrhard \\ IHI Charging Systems International GmbH, Engineering Division, Haberstraße 24, D-69126 Heidelberg, Germany \\ Correspondence should be addressed to Bernhardt Lüddecke, b.lueddecke@ihi-csi.de
}

Received 19 December 2011; Accepted 8 June 2012

Academic Editor: Nick C. Baines

Copyright ( $) 2012$ Bernhardt Lüddecke et al. This is an open access article distributed under the Creative Commons Attribution License, which permits unrestricted use, distribution, and reproduction in any medium, provided the original work is properly cited.

\begin{abstract}
Due to increased demands for improved fuel economy of passenger cars, low-end and part-load performance is of key importance for the design of automotive turbocharger turbines. In an automotive drive cycle, a turbine which can extract more energy at high pressure ratios and lower rotational speeds is desirable. In the literature it is typically found that radial turbines provide peak efficiency at speed ratios of 0.7 , but at high pressure ratios and low rotational speeds the blade speed ratio will be low and the rotor will experience high values of positive incidence at the inlet. Based on fundamental considerations, it is shown that mixed flow turbines offer substantial advantages for such applications. Moreover, to prove these considerations an experimental assessment of mixed flow turbine efficiency and optimal blade speed ratio is presented. This has been achieved using a new semi-unsteady measurement approach. Finally, evidence of the benefits of mixed flow turbine behaviour in engine operation is given. Regarding turbocharged engine simulation, the benefit of wide-ranging turbine map measurement data as well as the need for reasonable turbine map extrapolation is illustrated.
\end{abstract}

\section{Introduction}

Due to emission legislation, turbocharging of the automotive internal combustion engine is becoming common practice. This is not only the case for Diesel engines but also for gasoline engines. Turbocharging the internal combustion engine helps to achieve the required emission levels while maintaining suitable driving characteristics. The key requirements for new turbochargers are improved performance over a wide operating range while meeting increasingly strict packaging constraints.

To date radial flow turbines (RFTs) are mostly employed in turbocharger applications for automotive engines. This paper describes characteristics about mixed flow turbines (MFTs) leading to the conclusion that such turbines provide considerable advantages for fulfilling the demands in automotive turbocharger applications. In Figure 1, the mixed flow turbine geometry definition employed throughout this article is illustrated.

A dominant role for the turbine performance is incidence, that is, the difference between rotor inlet flow angle and blade angle at the rotor leading edge. According to Japikse and Baines [1], the optimum incidence for radial turbines is in the region of $-20^{\circ}$ to $-40^{\circ}$. Off-design operation of the turbine is playing a very prominent role in current turbocharger applications. Due to the intermittent exhaust gas pulse from the reciprocating engine, the turbocharger turbine operates under unsteady admittance. This is even more pronounced during engine transients. How the engine responds during these transients is important in providing driver satisfaction. Additionally, as combined downspeeding and downsizing concepts are introduced, the exhaust gas pulsation amplitudes increase, while the pulse frequency is lowered [2]. Therefore, all technologies that improve the efficiency over a wide range, as well as transient turbine behavior, are beneficial for turbocharger applications. In this regard mixed flow turbines, which have been successfully applied to modern gasoline applications [3-6], offer advantages. These advantages include a flat efficiency characteristic over a wide range as well as reduced inertia. This study describes the principal properties of such kinds of turbines, illustrates a method for evaluating wide map operation, 


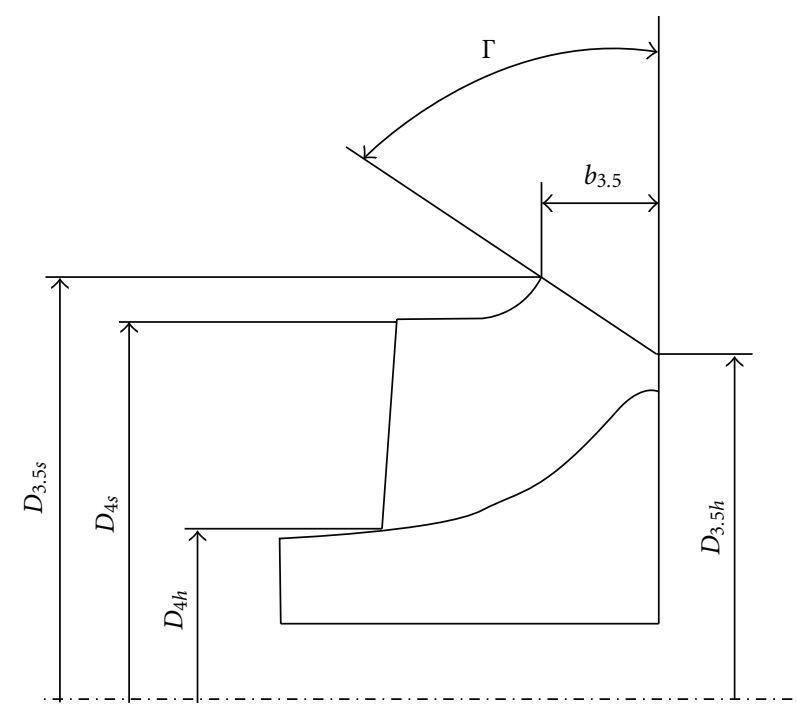

(a)

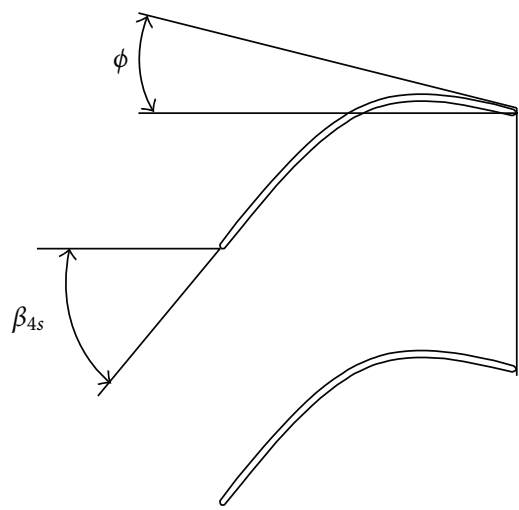

(b)

Figure 1: Turbine geometry definition.

and provides evidence of the advantages of mixed flow turbines for automotive turbocharger turbines. With regard to quasi-steady as well as transient engine simulation, the advantage of wide-ranging measurement data is illustrated. Moreover, standard hot gas stand measurement data are usually not sufficient for turbocharged engine simulation and extrapolation is needed. The desire for reasonable turbine map extrapolation methods is pointed out. This is closely linked to the correct knowledge of the blade speed ratio for turbine optimum efficiency. A derivation of this parameter is made in Section 3.

\section{Turbocharger Turbine Design}

It is common knowledge that radial turbines have their optimum efficiency at a blade speed ratio $\left(u_{3.5} / c_{s}\right)$ of around 0.7 , whereas the peak efficiency for mixed flow turbines is at lower blade speed ratios (e.g., [7]). For automotive turbocharger applications, the highest power is available at low $u_{3.5} / \mathcal{c}_{s}$, and hence the turbine efficiency in this range has a major influence on the performance of the turbocharged engine. Reducing incidence at low speed ratios can be achieved by reducing the relative rotor inlet flow angle and/or backward sweeping of the blade leading edge [8].

Theoretically the rotor inlet flow angle can be reduced by increasing $A / R$ of the turbine volute. However under pulsating flow conditions typical of automotive turbocharger applications this would lead to an excessive dissipation of exhaust gas kinetic energy. This is caused due to the volume of the turbine volute representing a substantial proportion of the overall volume of the exhaust manifold. Therefore, increasing $A / R$ would have an adverse impact on the turbocharger performance. As a result, pulse turbocharging concepts in passenger car applications usually apply the smallest possible turbine volutes, hence accepting an unfavourable inlet flow angle at low speed ratios in order to exploit the pulse energy.
Most of the radial turbines currently used have radial fibres due to mechanical constraints. The blade inlet angle is zero and the combination with a volute with small $A / R$ leads to an unfavourable incidence angle. This disadvantage can be avoided by applying mixed flow turbines which allow variation of the blade inlet angle while maintaining radial blade sections (compare Figures 2 and 8). Therefore the adverse inlet flow angle can - to some extent-be compensated by backward sweeping of the leading edge, avoiding detrimental incidence.

Mixed flow turbines offer the advantage of additional degrees of freedom for aero design compared to radial inflow turbines which usually adopt a radial stacking because of mechanical constraints. The blade inlet angle of mixed flow turbines can be nonzero even with radial blade sections. Therefore, with mixed flow turbines it is possible to realize more favourable efficiency characteristics compared to radial turbines with respect to automotive turbocharger applications. Mixed flow turbines can be designed having a lower inertia which positively contributes to transient response, yet still maintaining allowable stress limits. Stress levels in the turbine back disc are lower for a mixed flow design which supports higher allowable speeds.

Optimum incidence for mixed flow turbines occurs at lower blade speed ratios $u_{3.5} / c_{s}$. A similar impact could be achieved by backward sweeping the leading edge of a radial turbine. However due to mechanical constraints the amount of backward sweep for radial turbines is very limited [8]. Therefore, until today almost all radial turbines are characterized by radial fibres.

The aforementioned considerations are valid for steady flow conditions. However, turbines for automotive turbocharger applications are subject to highly pulsating inlet flows. The concept of pulse turbocharging, which is becoming increasingly popular, is aiming at optimum utilization of exhaust pulses through minimum manifold volume. As a consequence, the instantaneous turbine inlet conditions vary 

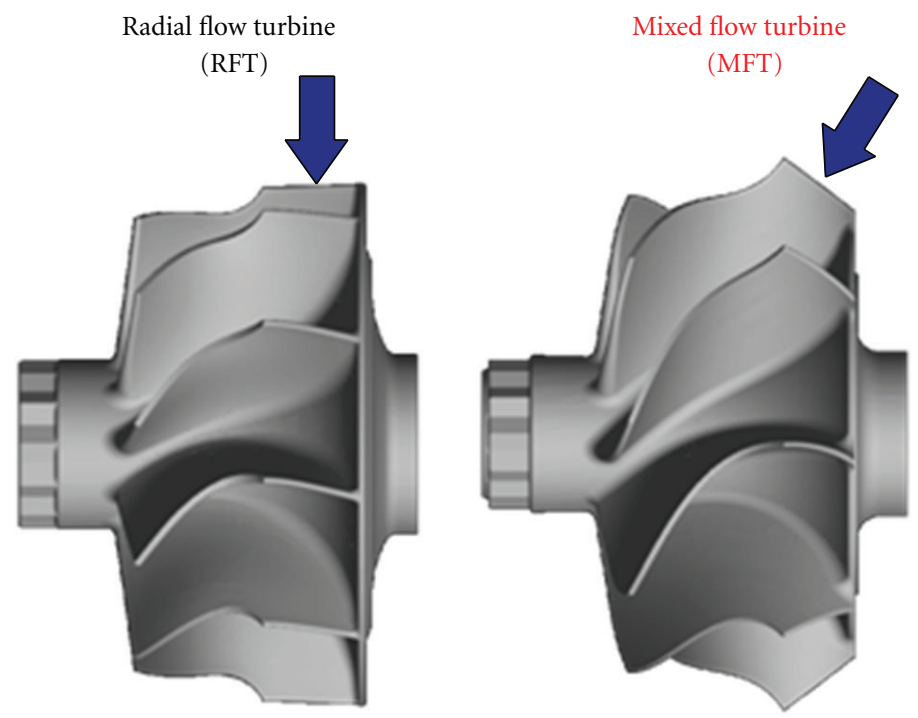

FIGURE 2: Radial versus mixed flow turbine.

over a wide range of flow rates. Therefore the development focus is not on achieving optimum design point efficiency but on achieving a turbine characteristic which offers a high efficiency over a wide range of flow conditions.

Looking at design point efficiencies would lead to the conclusion that radial turbines are superior compared to mixed flow turbines for the specific speeds relevant for automotive turbocharger applications (e.g., [9]). For high performance under pulsating operating conditions, the turbine efficiency has to be high for low blade speed ratios. For low blade speed ratios, the combination of high mass flow with a high efficiency leads to a high power [10]. In Section 3 basic considerations are given which support the aforementioned statements about mixed flow turbines.

\section{Simple Turbomachinery Fundamentals}

Throughout this work the nomenclature shown in Figure 3 is adopted. In the automotive industry, index or subscript 3 is commonly used for the turbine inlet position (stage inlet) while subscript 4 denotes turbine exit conditions. For the conditions at turbine wheel inlet, the subscript 3.5 is introduced.

Figure 4 displays velocity triangles at turbine wheel inlet and exit. The general velocity triangle (with inlet swirl) at impeller inlet is shown. Furthermore, two velocity triangles at turbine exit-one without exit swirl, while the other with exit swirl—are shown.

The equivalent (inlet) diameter of a MFT is defined by (1). This value is also used for circumferential velocity calculation of the mixed flow turbine wheel:

$$
D_{3.5}=\sqrt{\frac{D_{3.5 h}^{2}+D_{3.5 s}^{2}}{2}} .
$$

Total-to-static turbine efficiency is defined as:

$$
\eta_{T, \mathrm{ts}}=\frac{h_{3 t}-h_{4 t}}{h_{3 t}-h_{4 s, \mathrm{is}, \mathrm{is}}}=\frac{\Delta h_{\mathrm{tt}, \mathrm{stage}}}{\Delta h_{\mathrm{ts}, \mathrm{stage}, \mathrm{is}}} .
$$

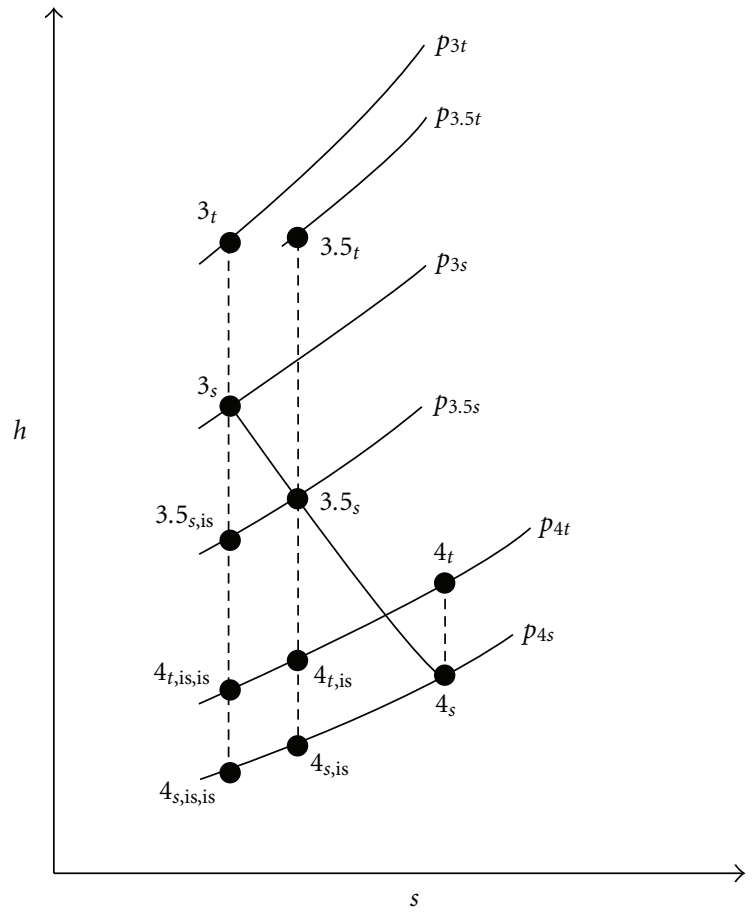

FIGURE 3: Enthalpy-entropy diagram of an expansion process within a turbine.

The isentropic spouting velocity, which could be achieved if the available total-to-static enthalpy drop would be converted into kinetic energy by an isentropic process, can be expressed as

$$
\frac{c_{s}^{2}}{2}=\Delta h_{\mathrm{ts}, \text { stage, is }}
$$

The blade loading factor is given by

$$
\psi=\frac{P_{T}}{\dot{m}_{T} u_{3.5}^{2}}=\frac{\Delta h_{\mathrm{t} t \text {,stage }}}{u_{3.5}^{2}}=\frac{c_{\varphi 3.5} u_{3.5}}{u_{3.5}^{2}}-\frac{c_{\varphi 4} u_{4}}{u_{3.5}^{2}} .
$$


Inlet: general velocity triangle

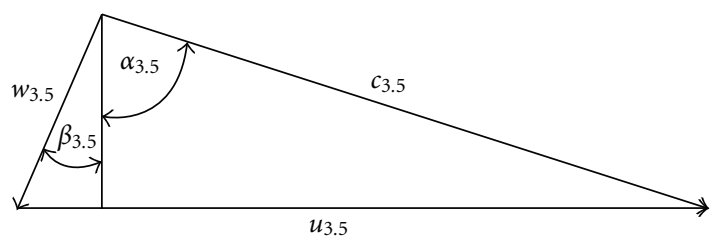

(a)

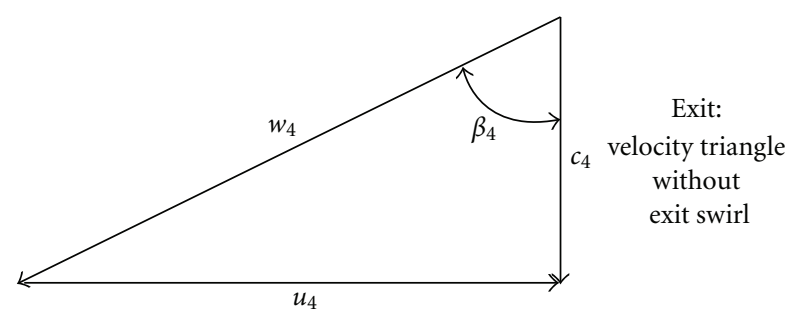

(b)

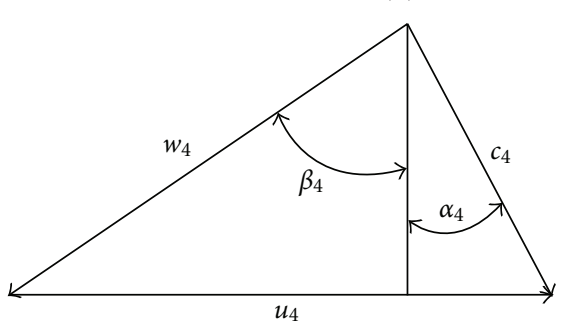

(c)

FIGURE 4: Velocity triangles at turbine wheel inlet and outlet.

The relationship between isentropic blade loading factor and the real blade loading factor is derived by

$$
\begin{aligned}
\psi & =\frac{\Delta h_{\mathrm{tt}, \text { stage }}}{u_{3.5}^{2}} \frac{\Delta h_{\mathrm{ts}, \text { stage, is }}}{\Delta h_{\mathrm{ts}, \mathrm{stag}, \mathrm{is}}} \\
& =\frac{\Delta h_{\mathrm{ts} \text { stage, is }}}{u_{3.5}^{2}} \frac{\Delta h_{\mathrm{tt}, \text { stage }}}{\Delta h_{\mathrm{ts}, \mathrm{stage}, \mathrm{is}}}=\psi_{s} \eta_{T, \mathrm{ts}} .
\end{aligned}
$$

If the exit swirl of a single radial or mixed flow turbine is small and circumferential blade velocity at rotor inlet is comparably higher than at rotor exit, the last term in (4) can be neglected, leading to

$$
\psi \approx \psi^{*}=\frac{c_{\varphi 3.5}}{u_{3.5}} .
$$

The relationship between stage loading and velocity triangle at rotor inlet is given by

$$
c_{\varphi 3.5}=u_{3.5}-c_{\mathrm{m} 3.5} \tan \left(\beta_{3.5}\right) .
$$

Knowing this, the total to static turbine efficiency can be written as

$$
\eta_{T, \mathrm{ts}}=\frac{\Delta h_{\mathrm{t} t \mathrm{stage}}}{\Delta h_{\mathrm{ts}, \mathrm{stage}, \mathrm{is}}}=\frac{\psi u_{3.5}^{2}}{c_{s}^{2} / 2}=2 \psi\left(\frac{u_{3.5}}{c_{s}}\right)^{2} .
$$

The term in brackets is commonly known as turbine blade speed ratio which is most commonly used for assessing turbine performance characteristics. Of key importance is the blade speed ratio at which turbine peak efficiency occurs.

For the ideal case, no losses, no incidence, and negligible swirl at turbine outlet are assumed.

(i) In absence of losses, the turbine efficiency equals unity:

$$
\eta_{T, \mathrm{ts}, \mathrm{opt}}=1 .
$$

(ii) No incidence, negligible swirl at turbine exit ( $\rightarrow$ velocity triangle), and perfect flow turning lead to

$$
\psi_{\mathrm{opt}} \approx \psi_{\mathrm{opt}}^{*}=1 \text {. }
$$

Then, the optimum value of blade speed ratio is given by

$$
\left(\frac{u_{3.5}}{c_{s}}\right)_{\mathrm{opt}}=\sqrt{\frac{1}{2}}=0.707 .
$$

This value of 0.707 is often quoted as the blade speed ratio value for optimum efficiency of a radial turbine. In fact, as can be seen by this derivation, the value of $\left(u_{3.5} / c_{s}\right)_{\text {opt }}$ is itself a function of maximum turbine efficiency, even if the blade loading factor is constant [11]. Additionally, optimum efficiency of a radial turbine occurs at loading factors below one. This means that the flow is approaching the rotor blades with positive incidence as shown in Figure 5.

The definition of incidence is given by

$$
i_{3.5}=\beta_{3.5}-\beta_{b 3.5} .
$$

By combination of (6) and (7), the loading is defined by

$$
\psi^{*}=1-\frac{c_{m 3.5}}{u_{3.5}} \tan \left(\beta_{3.5}\right) .
$$

Assuming a constant ratio of $c_{m 3.5} / u_{3.5}$ of 0.5 , by changing the incidence angle from $0^{\circ}$ to $25^{\circ}$, the blade loading for optimum incidence reduces to

$$
\psi^{*}{ }_{\text {opt,RFT }}=0.77 \text {. }
$$

Furthermore assuming a peak efficiency of 0.7 , the optimum blade speed ratio is calculated to

$$
\left(\frac{u_{3.5}}{c_{s}}\right)_{\text {opt,RFT,real }}=\sqrt{\frac{\eta_{T, \mathrm{ts}}}{2 \psi}}=\sqrt{\frac{0.7}{2 \cdot 0.77}} \approx 0.67 .
$$

Hence for these parameters and also for a radial turbine, the actual optimum efficiency is occurring at a blade speed ratio below 0.707 !

Considering mixed flow turbines, the consequences are as follows. For simplification, the characteristics of a MFT are explained assuming a RFT with back sweep as depicted in Figure 6.

The optimum flow turning within the backswept rotor is achieved for negative incidence, which in fact means almost radial inflow. Thus $\beta_{3.5} \approx 0^{\circ}$. The corresponding loading for optimum incidence is hence calculated to

$$
\psi_{\mathrm{opt}, \mathrm{MFT}}^{*}=1 .
$$




$$
\begin{aligned}
& \beta_{3.5}=-20^{\circ} \\
& \beta_{b 3.5}=0^{\circ} \\
& i_{3.5}=-20^{\circ}
\end{aligned}
$$
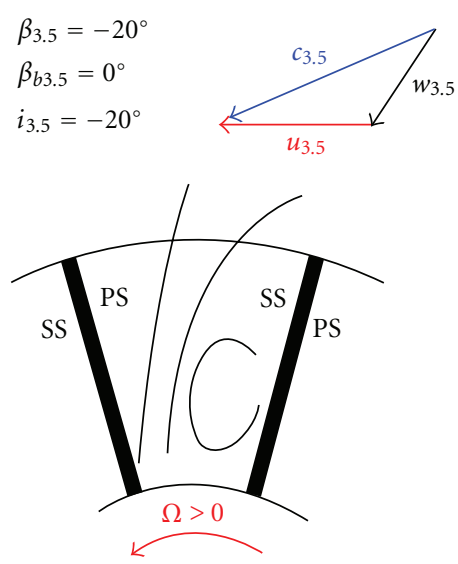

$$
\begin{aligned}
& \beta_{3.5}=20^{\circ} \\
& \beta_{b 3.5}=0^{\circ} \\
& i_{3.5}=20^{\circ}
\end{aligned}
$$
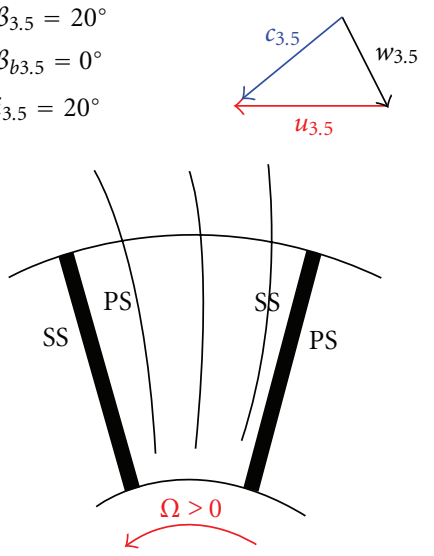

$\beta_{3.5}=0^{\circ}$
$\beta_{63.5}=0^{\circ}$
$i_{3.5}=0^{\circ}$
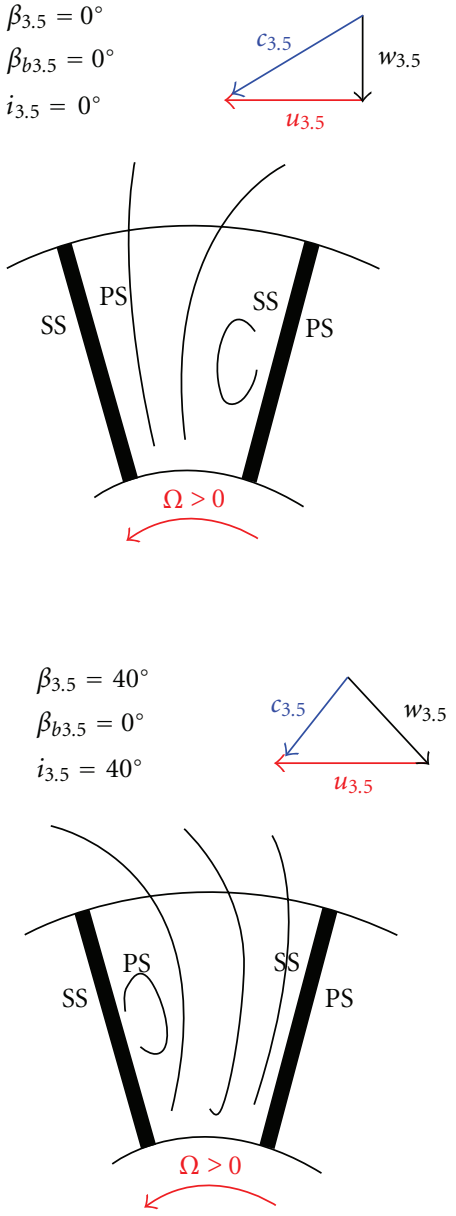

FIGURE 5: Radial flow turbine inflow characteristics for different incidence angles.

Assuming the same overall maximum turbine efficiency, the increased blade loading for optimum turbine efficiency leads to a shift in $\left(u_{3.5} / c_{s}\right)_{\text {opt }}$ according to

$$
\left(\frac{u_{3.5}}{c_{s}}\right)_{\text {opt,MFT,real }}=\frac{\eta_{T, \mathrm{ts}}}{2 \psi}=\sqrt{\frac{0.7}{2 \cdot 1}} \approx 0.59 .
$$

This relationship between blade speed ratio and turbine efficiency is illustrated in Figure 7. The independent parameter for the two plotted curves is blade loading. The two examples derived in the previous section as well as the often quoted value of $\left(u_{3.5} / c_{s}\right)_{\text {opt }}=0.707$ are highlighted.

The fact that optimum incidence is achieved at higher blade loading for mixed flow turbines has been reported by several authors. Even optimum blade loading values exceeding unity have been reported (e.g., $[12,13])$. The reason why mixed flow turbines behave like radial flow turbines with back sweep is illustrated in Figure 8. When a mixed flow turbine wheel is approached by a flow vector perpendicular to its inlet edge (green vector), a triangle between the radial and the actual flow direction can be drawn (lines: green, white, red). In other words, this means that the flow is not purely radial but has an axial component. By additionally leaning the blade with a nonzero rake angle, this triangle is rotated (lines: blue, white, red). The bottom line is that the resulting flow vector that approaches the blade is the one drawn in blue. While maintaining the radial stacking constraint, the effective flow angle of a radial flow is changed to be nonradial by adding an axial component. If an MFT is approached by a purely radial vector (red vector), the effect described above is not occurring.

For the radial rotor this means that due to the absence of an axial component in the vector approaching the rotor, the flow is by nature purely radial (red vector). The vector triangle described above is not established, and thus even when designing a nonzero rake angle, the "mixed-floweffect" is not achievable.

It should be emphasized that with regard to mechanical stress constraints, the distinct advantage of a mixed flow wheel over a radial flow wheel is that this nonzero blade inlet blade angle is achieved without violation of radial stacking condition. In addition to this, mixed flow turbine wheels offer the chance to design turbine wheels with reduced inertia. One key benefit is that the back disk is clearly reduced in diameter.

An analytical relationship between cone angle $(\Gamma)$, rake angle $(\phi)$, and blade angle $\left(\beta_{b}\right)$ is given by

$$
\tan \left(\beta_{b}\right)=\cos (\Gamma) \tan (\phi) .
$$

These theoretical considerations of turbine characteristics are in agreement with measurements and supported by 


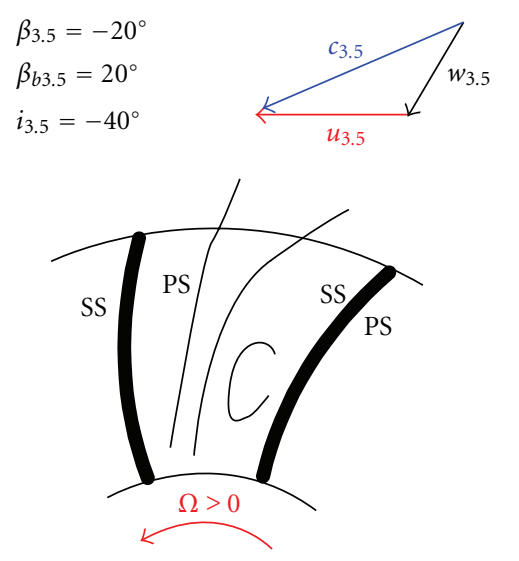

$$
\begin{aligned}
& \beta_{3.5}=0^{\circ} \\
& \beta_{b 3.5}=20^{\circ} \\
& \mathrm{i}_{3.5}=-20^{\circ}
\end{aligned}
$$
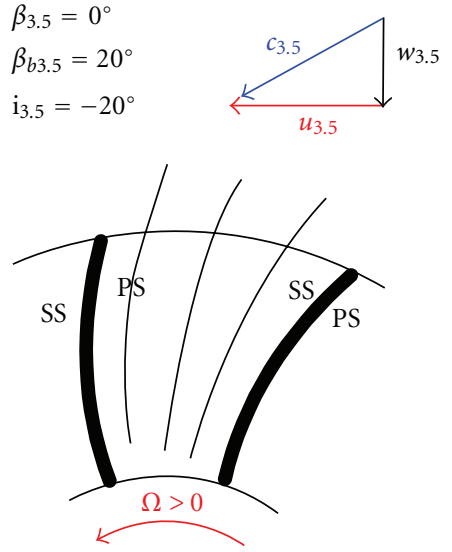

$$
\begin{aligned}
& \beta_{3.5}=20^{\circ} \\
& \beta_{b 3.5}=20^{\circ} \\
& i_{3.5}=0^{\circ}
\end{aligned}
$$

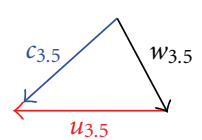

$$
\begin{aligned}
& \beta_{3.5}=40^{\circ} \\
& \beta_{b 3.5}=20^{\circ} \\
& i_{3.5}=20^{\circ}
\end{aligned}
$$
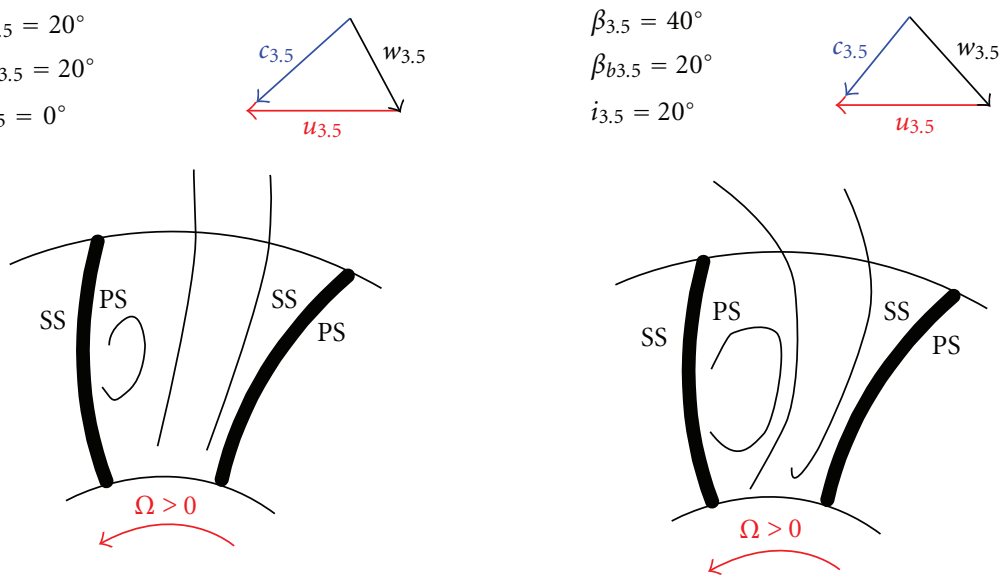

FIGURE 6: Backswept RFT/MFT inflow characteristics for different incidence angles.

several studies (e.g., $[7,13]$ ). For example, Figure 9 shows a comparison of radial and mixed flow turbine efficiency versus blade speed ratio. The shift to lower values of blade speed ratio can clearly be recognized.

This characteristic of mixed flow turbines is desirable especially for the requirements of automotive turbocharger applications. Under pulsation conditions, the maximum exhaust gas enthalpy is available for high pressure ratios, occurring directly after exhaust valve opening. As turbine speed does only slightly change - if at all—during an engine cycle, the high pressure ratio results in low values of $u_{3.5} / c_{s}$. Therefore, it is important to have high efficiencies for these conditions [10].

In the current work the enthalpy-based definition of the degree of reaction is adopted:

$$
R=\frac{\Delta h_{\mathrm{s}, \text { rotor }}}{\Delta h_{\mathrm{tt}, \mathrm{stage}}}=\frac{h_{3.5 s}-h_{4 s}}{h_{3 t}-h_{4 t}}
$$

Assuming that within the stator, that is, from station 3 to station 3.5, no losses occur (e.g., $h_{3 t}-h_{3.5 t}=0$ ), (19) can be rearranged to

$$
R=\frac{\left(h_{3.5 t}-c_{3.5}^{2} / 2\right)-\left(h_{4 t}-c_{4}^{2} / 2\right)}{h_{3 t}-h_{4 t}}=1-\frac{c_{3.5}^{2}-c_{4}^{2}}{2\left(h_{3 t}-h_{4 t}\right)} .
$$

Together with (4) the velocity triangles shown in Figure 4 and the assumptions that the investigated turbine stage has no losses $\left(h_{3.5 t}=h_{4 t}\right)$, negligible exit swirl $\left(c_{\varphi 4}=0\right)$, and $c_{r 3.5}=c_{z 4}$ (no diffusion, no acceleration within a radial rotor), (20) can be rearranged to

$$
\begin{aligned}
R & =1-\frac{c_{3.5}^{2}-c_{4}^{2}}{2\left(c_{\varphi 3.5} u_{3.5}\right)}=1-\frac{\left(c_{\varphi 3.5}^{2}+c_{r 35}^{2}\right)-\left(c_{\varphi 4}^{2}+c_{z 4}^{2}\right)}{2\left(c_{\varphi 3.5} u_{3.5}\right)} \\
& =1-\frac{c_{\varphi 3.5}}{2 u_{3.5}}=1-\frac{\psi^{*}}{2} .
\end{aligned}
$$

From this, a relationship between $\left(u_{3.5} / c_{s}\right)_{\text {opt }}$ and the degree of reaction, depending on the turbine efficiency, is derived:

$$
\left(\frac{u_{3.5}}{c_{s}}\right)_{\text {opt }}=\sqrt{\frac{\eta_{T, \text { ts }}}{4(1-R)}} .
$$

In Figure 10 the interdependency of these parameters is plotted. The highlighted symbol in the graph shows again 


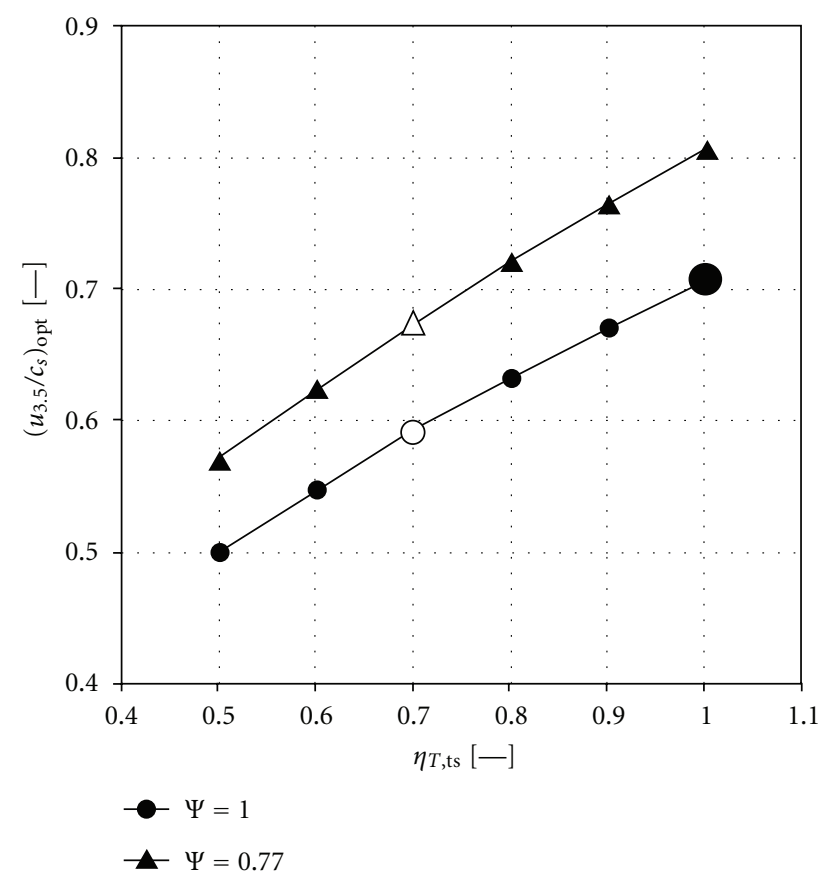

Figure 7: Optimum $u_{3.5} / c_{s}$ versus assumed stage efficiency for two different blade loadings.

the frequently quoted optimum value of 0.707 as described before. Furthermore, the graph shows clearly that the optimum values of $u_{3.5} / c_{s}$ versus the degree of reaction for nonideal efficiencies can be expected to be lower in real turbine configurations. Depending on the degree of reaction of the chosen turbine stage design, the optimum blade speed ratio can be modified. Moreover, in turbocharger applicationsincluding fixed turbine geometry configurations-it has to be considered that the variation of inlet pressure over time caused by the intermittent exhaust pulses from the reciprocating engine do cause a variation in degree of reaction during operation. This means that there will not be one fixed value of optimum blade speed ratio that describes the on-engine turbine behaviour (compare [14]).

Figure 11 shows the measured mass flow parameter and efficiency versus expansion ratio of a mixed flow turbine in comparison with an equivalent radial turbine. The data was obtained on a hot gas stand under quasi-steady flow conditions and is subject to heat flow effects typical for measurements of small turbocharger turbines. This graph already indicates the beneficial characteristics of mixed flow turbines.

From the theoretical analysis performed above, there is sufficient reason for investigating the behaviour of turbines over a very wide operating range in more detail.

A potential procedure for doing so is described in the following Section.

\section{Steady Wide Mapping Results for a Mixed Flow Turbine}

This study was undertaken for a small mixed flow turbine for automotive gasoline engine application. In [15], a new, simple method for wide mapping by variation of turbine inlet temperatures has been presented. By minimising the influence of heat flows, a quasi-adiabatic turbine map was evaluated from measured data. The simple heat transfer model introduced in [15] showed good agreement with the approaches of other authors [16]. The resulting contour map after heat transfer correction is shown in Figure 12. This map is not corrected for friction losses in the bearing system.

The turbine pressure ratio is plotted versus blade speed ratio. The colour and the isolines separate areas of same total to static turbine efficiency. Optimum efficiency is achieved within a range of $u_{3.5} / c_{s}$ between 0.56 and 0.62 , thus much lower than usually cited in the literature [9].

Furthermore it can be seen that according to theory the optimum blade speed ratio where the turbine offers best efficiency is increasing with pressure ratio.

$P I_{T, \text { ts }}$ can (amongst others) be interpreted as a flow coefficient and gives information about exit dynamic head.

$P I_{T, \text { ts }}$ and $u_{3.5} / c_{s}$ are also related to several loss mechanisms within the stator and rotor. Therefore it is justified to assess stage performance (more precisely: efficiency) using these parameters.

For a fixed geometry (wastegated) turbine, efficiency is only depending on flow coefficient, loading coefficient, and Reynolds' number. MFP and pressure ratio are strongly coupled. As the turbine exit pressure is typically almost ambient pressure for hot gas stand tests, $P I_{T, \text { ts }}$ also gives direct information about exit dynamic head, when turbine inlet temperature is fixed. The blade speed ratio can be interpreted as loading coefficient.

\section{Semi-Unsteady Turbine Efficiency Measurement Approach for Wide Mapping of a Mixed Flow Turbine}

Based on the steady wide mapping results shown above, a new, instantaneous method for measurement of efficiency at very low values of $u_{3.5} / c_{s}$ was developed. The so-called high inertia rotor (HIR) approach of the IHI Charging Systems International (ICSI) is based on acceleration measurement of a rotor which has a significantly higher inertia than the standard turbocharger rotor. To achieve this, the compressor wheel was replaced by a bladeless, zero work, high inertia impeller as shown in Figure 13.

By measuring the instantaneous speed and utilizing the known rotor inertia, the instantaneous turbine acceleration power is directly evaluated. This instantaneous acceleration power is compared against an almost constant isentropic enthalpy difference, generated by the hot gas burner of the test bench. As mass flow was measured and held constant, temperature at turbine inlet was controlled by setting the heating unit to constant power. This was rechecked by the temperature measurement. However, the applied thermocouples were not fast response and could not determine accurately the temperature with respect to time due to their thermal inertia. Pressure measurements were done with "fast response" pressure transducers to control whether pressure ratio varies during acceleration and to 

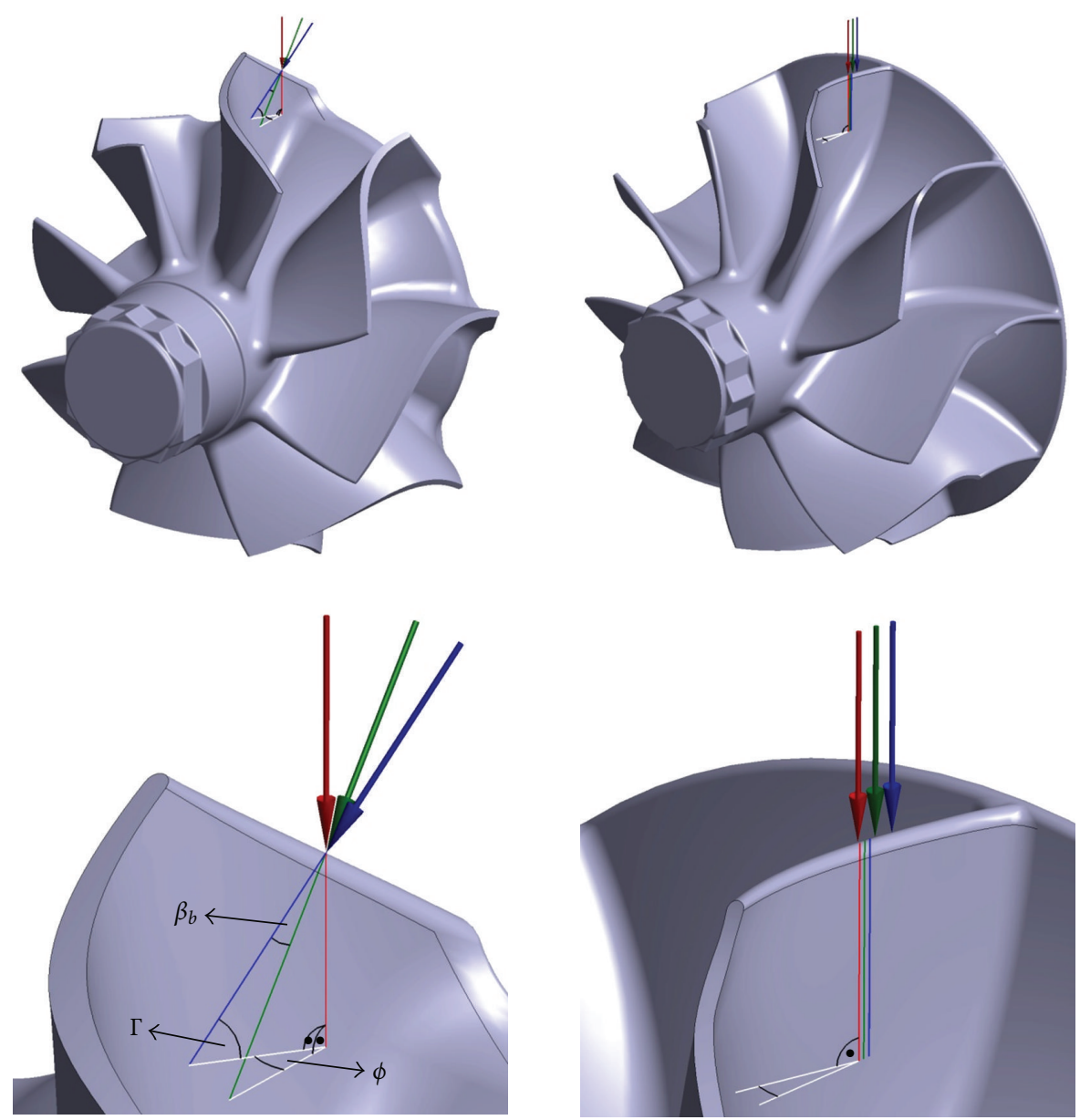

FIGURE 8: Degrees of freedom for mixed flow and radial flow turbines.

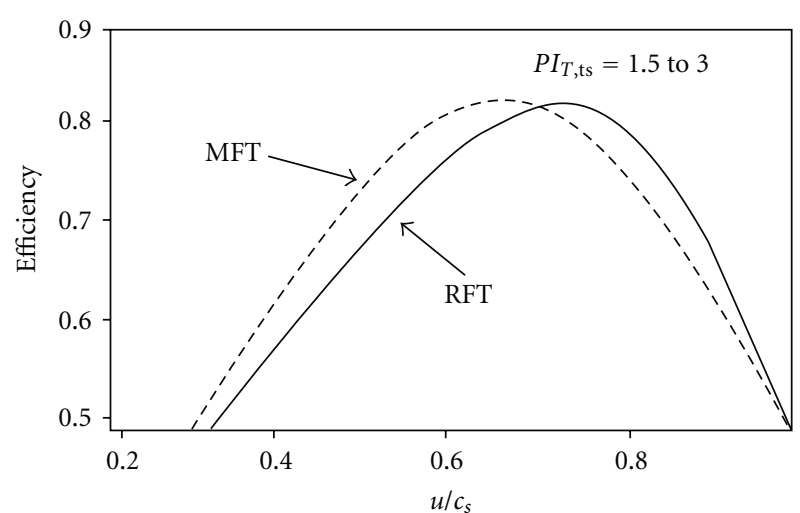

Figure 9: Turbine efficiency as a function of blade speed ratio for radial and mixed flow turbines [7].

allow for a phase correction between the pressure before and after the turbine. This was done with calibrated piezoresistive absolute pressure transducers [17]. The absolute pressure value of the fast transducers was cross-checked, with the signal of the standard "slow response" pressure sensor signal before the HIR acceleration was started. A picture of the test-bench setup is shown in Figure 14.

Turbine housing as well as all hot gas and measurement pipes as insulated to minimize heat transfer between the turbocharger and the test cell environment. Furthermore, turbine inlet temperature, oil conditioning, and water cooling were set to constant low values to minimize heat transfer. Initially, the HIR is locked and the desired turbine pressure ratio and turbine inlet temperature are set. After starting of the transient measurement system, the rotor is released and accelerates. An automatic shutdown procedure is applied to prevent overspeed of the HIR.

Regarding maximum rotational speed, two main aspects have to be considered.

(i) Firstly maximum allowable speed must not be exceeded, to avoid any damage of the HIR itself as well as the bearing system. It is clear that the rotor dynamics of such a HIR system are very different from a conventional turbocharger rotor.

(ii) Secondly, the speed has to be low enough; that is, elastic deformation of the rotor does not change the moment of inertia. Otherwise, the speed signal could not be used for turbine net power measurement during acceleration of the rotor.

A typical result of the instantaneous measurements, for a constant $P I_{T, \text { ts }}=1.4$, is shown in Figure 15 .

The calculated values for torque, power, and efficiency for very low values of $u_{3.5} / c_{s}$ are not reliable. This is indicated 


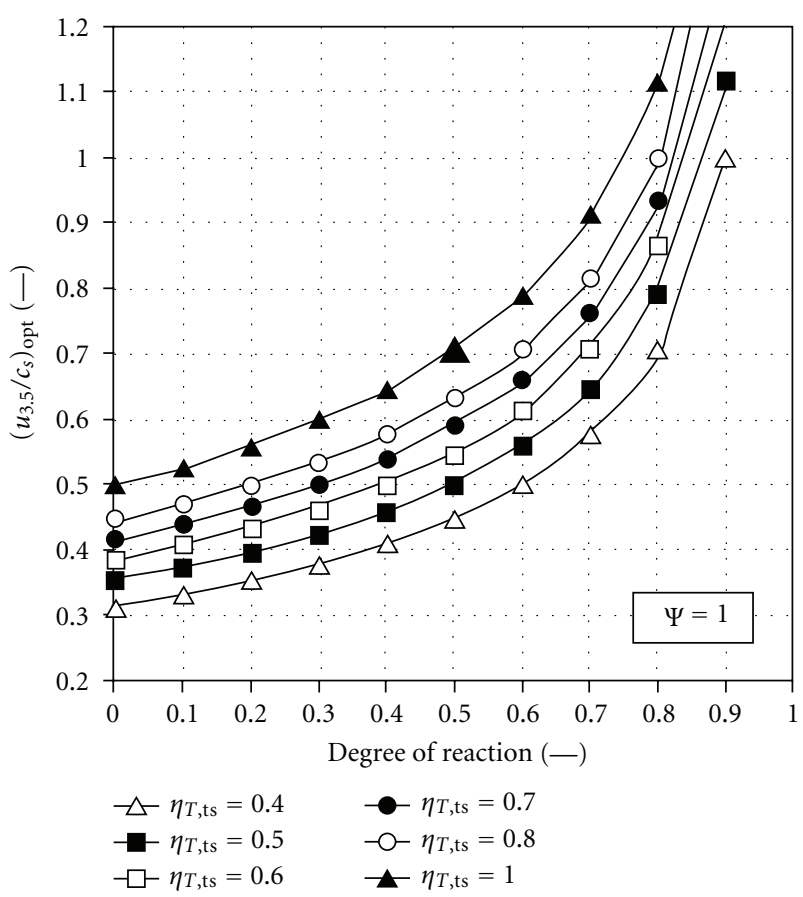

Figure 10: Optimum $u_{3.5} / c_{s}$ versus degree of reaction in dependency on turbine efficiency.

on the very left side of the graph. The journal bearings are starting to rotate and the oil film is developing. Thus values of $u_{3.5} / c_{s}$ lower than 0.08 have to be omitted. The highest possible value of blade speed ratio is limited by the maximum rotational speed of the HIR and depends on the applied turbine pressure ratio. The higher the desired $P I_{T, \mathrm{ts}}$, the lower the maximum of the $u_{3.5} / c_{s}$ that can be achieved due to stress limitations.

The evaluation procedure for instantaneous torque, power, and efficiency is given as follows.

The rotor acceleration is calculated by

$$
\ddot{\varphi}(t)=\frac{\omega(t)}{\Delta t}=2 \pi \cdot \frac{n_{T}(t)-n_{T}(t-1)}{\Delta t} \cdot \frac{1}{60} .
$$

The instantaneous torque can then be calculated, if rotor inertia is known. The rotor inertia of the HIR is about 28 times higher compared to a conventional turbocharger rotor:

$$
T(t)=J \cdot \ddot{\varphi}(t) .
$$

Instantaneous turbine power can then be calculated according to

$$
P_{T, \mathrm{tm}}(t)=T(t) \cdot \omega(t)
$$

The instantaneous power has to be compared with the almost constant burner power or ideal total-to-static enthalpy flow:

$$
\begin{aligned}
P_{\mathrm{ts}, \mathrm{is}}(t)= & \dot{m}_{\mathrm{gas}}(t) \cdot c_{p, \mathrm{gas}}(t) \cdot T_{3}(t) \\
& \cdot\left(1-\left(\frac{1}{\pi_{T, \mathrm{ts}}(t)}\right)^{\left(\kappa_{g}(t)-1\right) / \kappa_{g}(t)}\right) .
\end{aligned}
$$

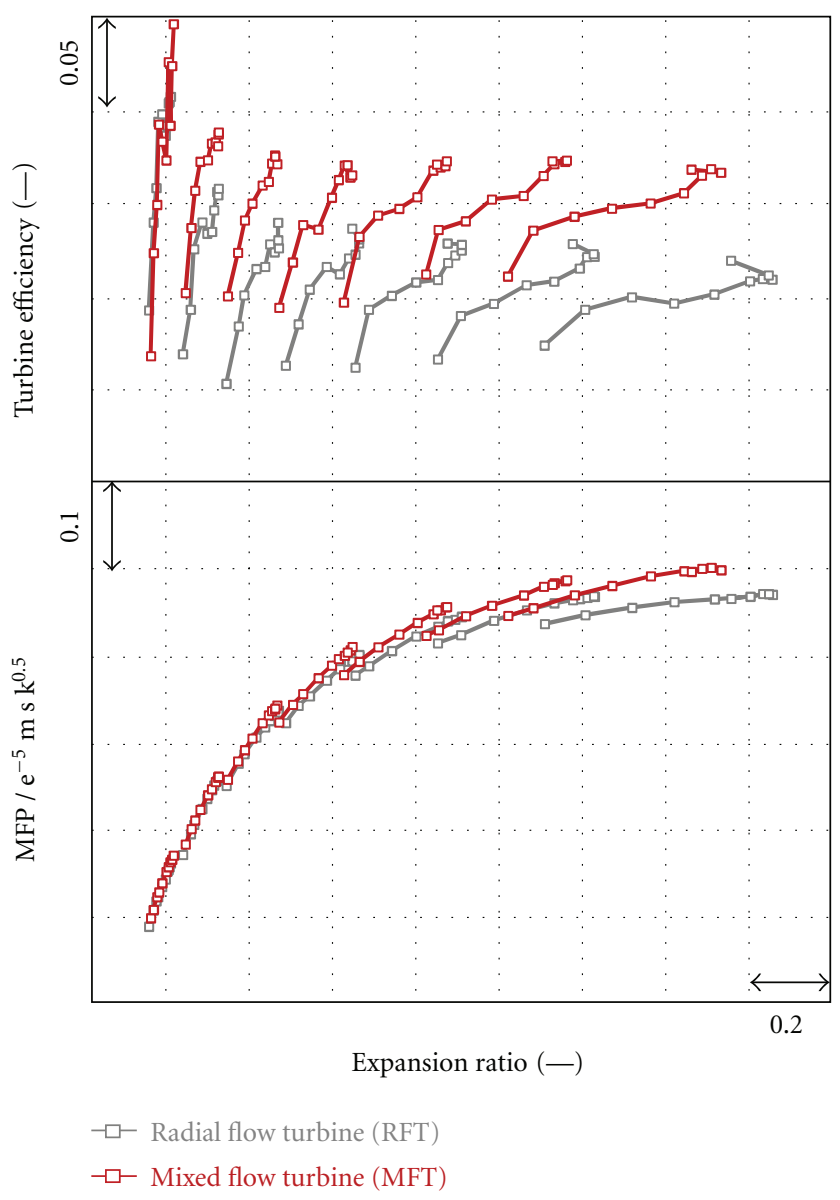

FIGURE 11: Turbine performance comparison: mixed flow versus radial flow turbine.

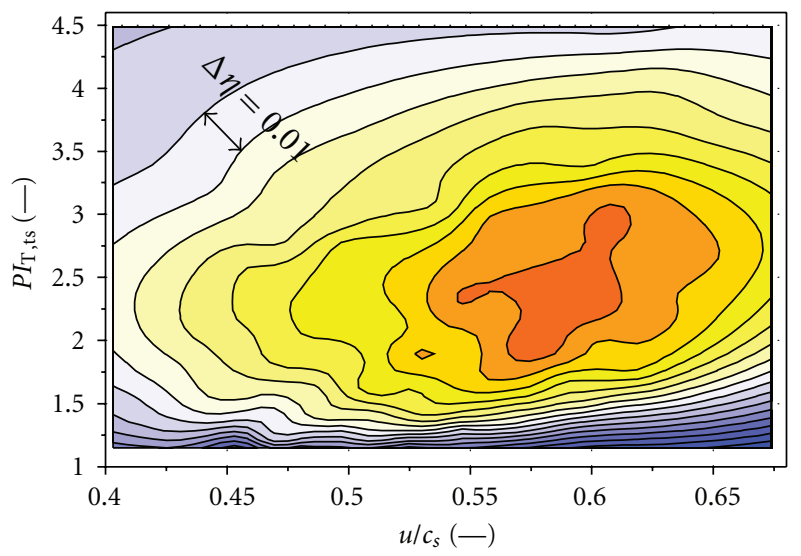

Figure 12: Mixed flow turbine efficiency contour plot [15].

The instantaneous thermomechanical total-to-static turbine efficiency is then defined by

$$
\eta_{T, \mathrm{ts}, \mathrm{tm}}(t)=\frac{P_{T, \mathrm{tm}}(t)}{P_{\mathrm{ts}, \mathrm{is}}(t)} .
$$

These "semi-unsteady" results are compared with the results of the steady wide mapping results. To do this, the contour 


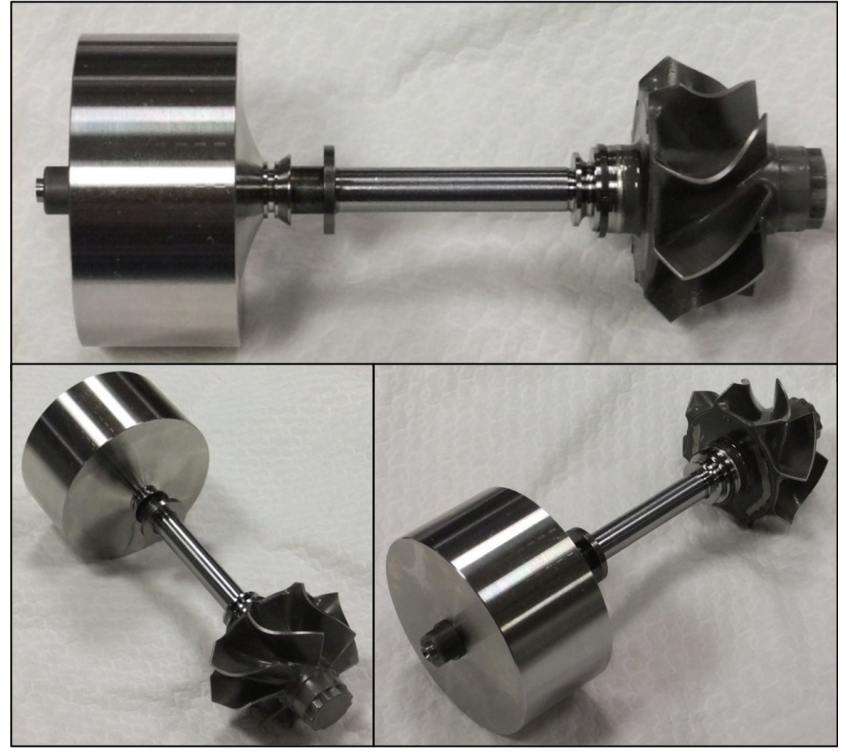

FIGURE 13: High inertia rotor (HIR) assembly.

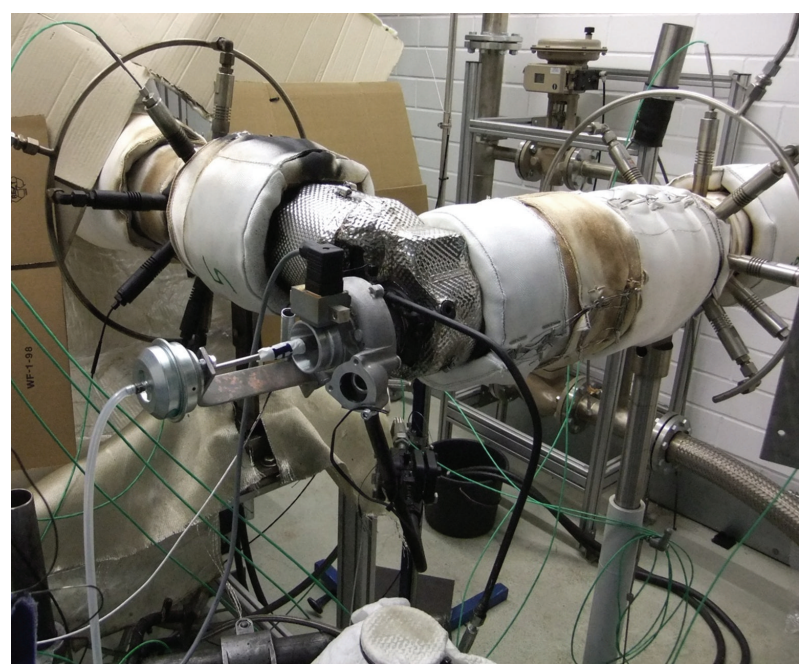

FIGURE 14: Test setup for unsteady turbine performance measurement.

plot of Figure 12 is intersected at a pressure ratio of 1.4. Then a single curve of efficiency as a function of blade speed ratio obtained. This curve is compared to the results already shown in Figure 15. Additionally, to judge the quality of the instantaneous measurement and of the extrapolation, the socalled runaway speed has also been measured (Figure 16). This was done as described by Smiljanovski et al. [18], and the corresponding measured value is also included in Figure 17. A zero-friction impeller (ZFI) replaces the compressor wheel, and the resulting speed that is measured for different turbine pressure ratios is the speed, where turbine power and friction power are equal. The results of the runaway speed measurements for two different turbine inlet temperatures and several pressure ratios are presented in Figure 16. It can be seen that for pressure ratios higher than 1.6 the runaway speed remains constant.

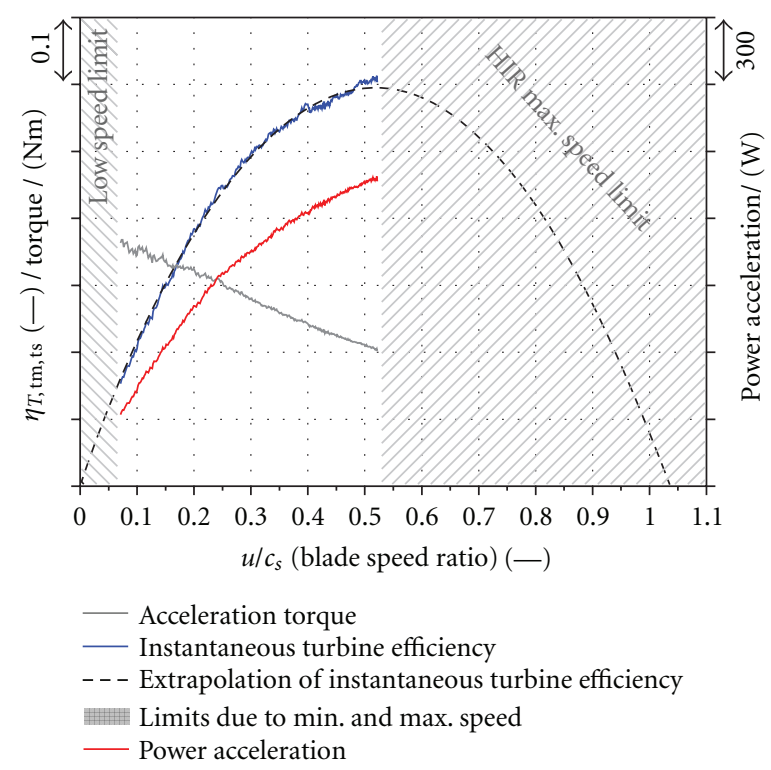

FIGURE 15: Typical result of an unsteady HIR measurement.

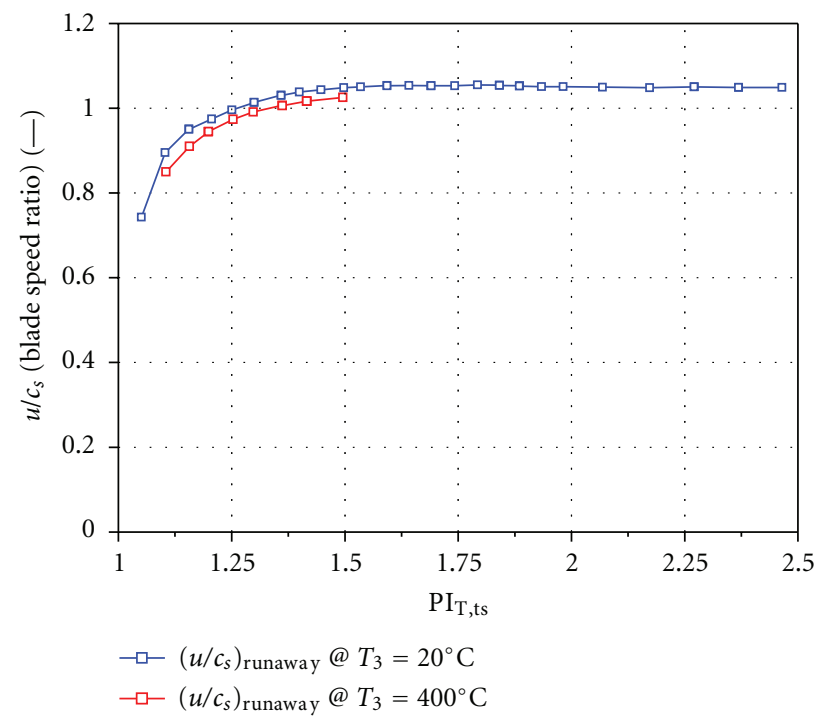

FIGURE 16: Runaway speed measurements for two turbine inlet temperatures.

For a pressure ratio of 1.4 and a turbine inlet temperature of $20^{\circ} \mathrm{C}$, a runaway blade speed ratio of about 1.04 was recorded.

From analysing Figure 17, it can be stated that the steady and unsteady results give a consistent picture of turbine efficiency characteristics. It also proves the values of blade speed ratio, where optimal efficiency is reached.

However, some deviation exists which can be explained. The steady results have been collected by the so-called "turbine net efficiency approach" [19], using the measured compressor power to calculate thermo-mechanical turbine efficiency. Heat transfer effects have been corrected by a simple heat transfer model [15], which in general gives very reasonable results in turbine efficiency trend. Opposed 


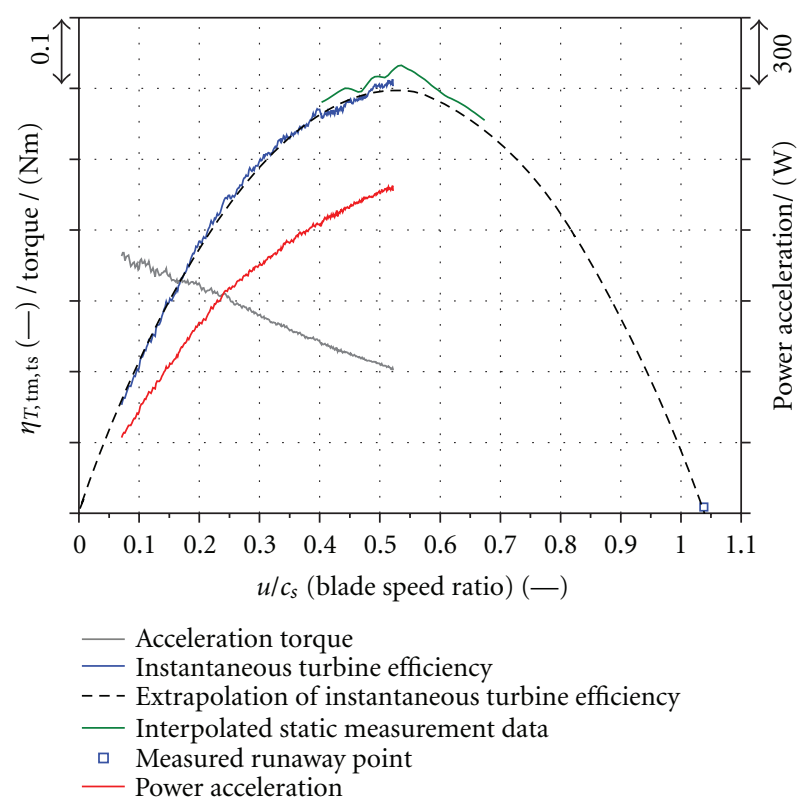

FIgURE 17: Comparison of steady and unsteady test results.

to this, the unsteady approach does not need a heat transfer correction, as measurements have been carried out at very low turbine temperatures and the turbine power measurement is done by measuring acceleration power. But as already mentioned, for this approach, no compressor wheel exists, and hence the axial thrust is different compared to the steady-state wide map efficiency measurements. This has an impact on bearing losses and thus thermomechanical turbine efficiency.

Regarding unsteady turbine operation, it is to note that due to the almost constant turbine pressure ratio during acceleration, no filling and emptying effects within the turbine scroll have to be expected. Thus, although this is an unsteady measurement, the problems that are encountered during efficiency measurement under pulsed conditions are overcome. Thus, the experimental approach presented here is labelled "semi-unsteady."

\section{Turbine Performance under Pulsating Flow Conditions}

Due to the exhaust gas pulse from the intermittent operation of the reciprocating engine, the turbocharger turbine operates under unsteady admittance. In Figure 18 the turbine operation during a typical engine cycle is shown. The green filled diamonds represent the available measured data points. The solid blue lines show the data fitted extrapolation, and the red line gives the unsteady turbine operation during engine cycle. The figure illustrates that usually the limited measured data has to be extrapolated far beyond the available range and underlines the importance of accurate extrapolation techniques, what is consistent with findings in [20, 21].

Thus, the correct prediction of engine steady operation, as well as unsteady operation or even vehicle acceleration

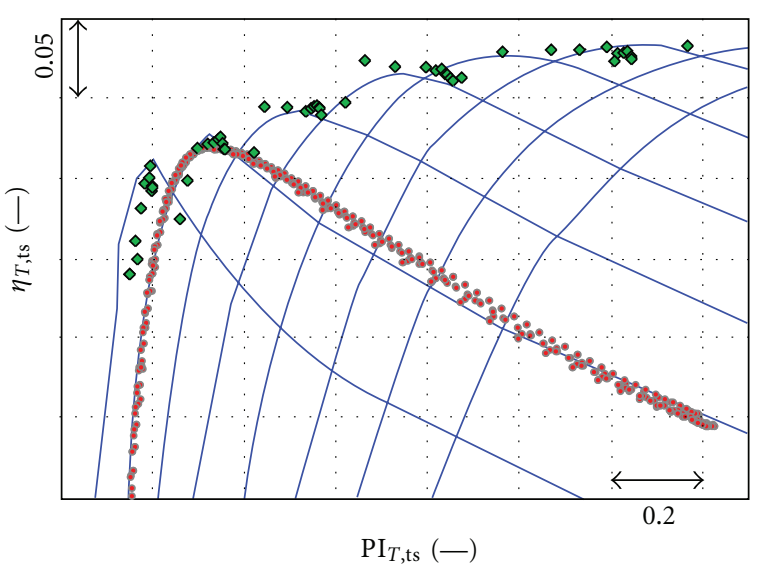

$\diamond$ Standard hot gas test bench data

- Extrapolated hot gas test bench data

- Turbine operation during engine cycle simulation

FIGURE 18: On-engine turbine operation.

behavior, is strongly depending on sensible and correct extrapolation.

A wide map measurement of turbine data can help to avoid the need for extrapolation. However, usually a wide map measurement is not available. A wide map measurement can be used to develop improved extrapolation algorithms. In general the turbine efficiency data to be extrapolated should not contain friction influence from the bearing system. Friction is not related to aerodynamic parameters but to real shaft speed as well as to thrust load.

However, standard hot gas stand turbine efficiency data usually contains friction data due to the measurement method. Thus, modelling of bearing friction depending on shaft speed, and thrust load can also be a source of error for extrapolation.

In this section it is investigated how various turbine characteristics and designs affect the on-engine operation. From the above sections it is known that the efficiency characteristics of mixed flow turbines can be advantageous for automotive turbocharger applications.

Figure 19 illustrates the calculated increase of boost pressure versus time using the in-house engine simulation code ITES ("IHI Turbocharged Engine Simulation") by Ikeya et al. [22].

This simulation program is capable of predicting turbocharged engine performance under steady and transient conditions. ITES is focused on the detailed modelling and numerical description of the turbocharger. The study shown in Figure 19 aims to identify turbine configurations which are advantageous for transient operation. The study was performed on a representative four-cylinder gasoline engine for passenger cars with a load step at $1500 \mathrm{rpm}$. As already mentioned, transient operation is of major importance since steady-state operation of the turbocharger is basically not existent. This is even more pronounced since speeding up a vehicle from stand still as well as satisfactory acceleration during vehicle drives are the most important events in evaluating driver's satisfaction. Therefore, all technologies 
that improve the transient turbine behaviour are beneficial for turbocharger applications.

All results are compared to a mixed flow turbine rotor made from conventional nickel-base alloy. This is referred to as the base configuration.

The effects that have been investigated are inertia and turbine efficiency. A clear advantage can be seen when comparing the base configuration with a turbine variant made from gamma titanium aluminide $(\gamma$-TiAl). Since the density of this material is much lower compared to nickelbase alloys, the rotor inertia is reduced and hence the acceleration of such a turbine is notably improved and helps to increase the boost pressure rise. It has to be mentioned that this advantage might be compromised due to more severe manufacturing constraints. Due to the unfavourable castability of $\gamma$-TiAl and its lower ductility, it is susceptible to foreign object damage. This almost inevitably compromises the aerodynamic design. For example, in Figure 20 two turbine wheel designs - one for nickel-base alloy and one for $\gamma$ TiAl — with identical swallowing capacity are compared. The grey wheel represents the "standard" nickel-base alloy design, while the superimposed red single blade shows the $\gamma$-TiAl design that requires higher material thickness. To achieve the same flow capacity, the blade angle distribution needs to be modified for readjustment of the throat area of the wheel.

The $\gamma$-TiAl turbine wheel from this comparison still has a $46 \%$ lower polar moment of inertia compared to the nickelbase alloy wheel. Regarding the rotor assembly (turbine wheel and shaft plus compressor wheel), this advantage reduces but still is about $30 \%$. In the predicted values shown in Figure 20, because of the aforementioned $\gamma$-TiAl design constraints a turbine efficiency penalty of $5 \%$ is assumed. Any benefit achieved by the reduced inertia is offset by the drop in efficiency. Additionally, steady-state engine brake specific fuel consumption will deteriorate as a result of decreased turbine efficiency. Consequently, depending on individual design requirements, using this material might be neither favourable nor desirable for certain applications.

Please note that the simulation results also depend on the investigated engine load step and especially the starting conditions of the load step for example, acceleration from stand still profits more from reduced inertia.

The effect of modifying the characteristics of the turbine map, the main topic of the current work, was also investigated. Compared to the base configuration, a variant with reduced $\left(u_{3.5} / c_{s}\right)_{\text {opt }}$ values was simulated. The peak efficiency of such a (mixed flow) turbine is not necessarily increased as indicated by Figure 7, but the map area where peak efficiency is reached is modified. It can clearly be noted that this modification of the turbine stage behaviour is of benefit for providing quick boost pressure rise. Similar findings are reported in [23]. Of course, a turbine variant offering bothoptimized map and low inertia-shows the best transient response.

\section{Summary and Conclusion}

Due to increasingly higher demands for improved fuel economy of passenger cars, low-end and part-load performance is

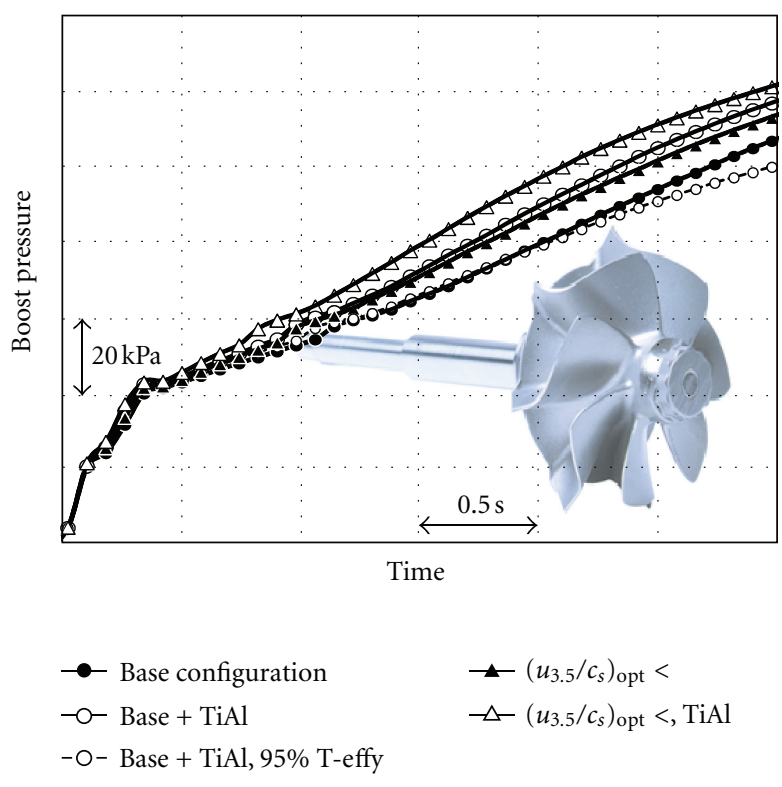

Figure 19: Increase of boost pressure versus time depending on different turbine configurations.

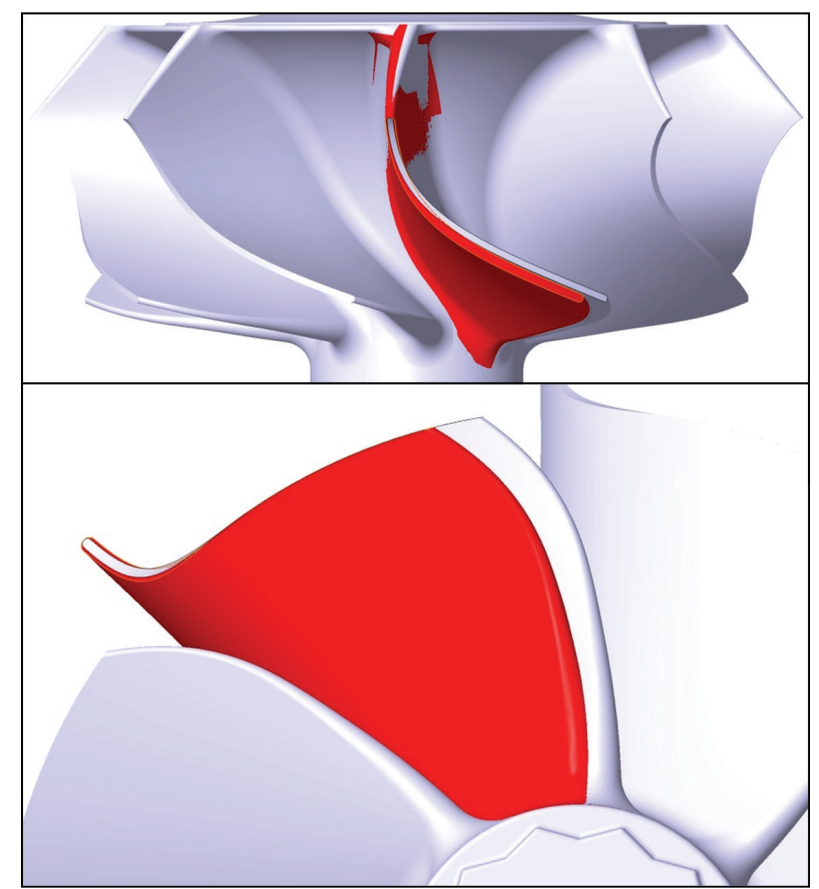

FIGURE 20: Comparison of nickel-base alloy and $\gamma$-TiAl turbine wheel design.

of key importance for the design of automotive turbocharger turbines. In an automotive drive cycle, a turbine which can extract more energy at high pressure ratios and lower rotational speed is desirable.

It is commonly quoted that a radial turbine provides peak efficiency at blade speed ratios of about 0.7 , but at high pressure ratios and low rotational speeds the blade speed ratio will be low and the rotor will experience high values of 
positive incidence at the inlet. The present study shows that even for radial turbines the blade speed ratio where optimum efficiency is reached is usually lower than the commonly quoted blade speed ratio of 0.7 . The present work gives theoretical justification and experimental evidence that for mixed flow turbines optimum efficiency can be obtained at even lower blade speed ratios. This can be attributed to a more favourable inlet blade angle, swallowing capacity and inertia when compared to a radial design.

The present study shows that mixed flow turbines have key advantages for automotive turbocharger applications as they have improved performance at low blade speed ratios. This means that a significant portion of the pulse energy available in the exhaust gas can be utilized. The behaviour of a mixed flow turbocharger turbine was investigated by steady-state wide mapping and also by employing a new, semi-unsteady measurement approach. It was found that the unsteady approach shows very good agreement with the steady and runaway measurements. It was theoretically derived that the blade speed ratio for optimum efficiency of a mixed flow turbine is far below the commonly cited value of 0.7 . This was also proven experimentally. Finally an investigation of how this could improve on-engine behaviour was described. The benefit of low-inertia mixed flow turbocharger turbine wheels has been clearly demonstrated.

\section{Nomenclature}

$\begin{array}{ll}p: & \text { Static pressure }(\mathrm{Pa}) \\ p_{\text {tot }}: & \text { Stagnation pressure }(\mathrm{Pa}) \\ u_{3.5} / c_{s}: & \text { Blade speed ratio }(-) \\ P I(\text { also } \pi): & \text { Pressure ratio }(-) \\ c: & \text { Velocity in stationary frame }(\mathrm{m} / \mathrm{s}) \\ w: & \text { Velocity in rotating, relative frame }(\mathrm{m} / \mathrm{s}) \\ u: & \text { Blade speed }(\mathrm{m} / \mathrm{s}) \\ \Delta h: & \text { Enthalpy difference }(\mathrm{J} / \mathrm{kg}) \\ C: & \text { Compressor } \\ D: & \text { Diameter } \\ c_{s}: & \text { Isentropic spouting velocity }(\mathrm{m} / \mathrm{s}) \\ R: & \text { Degree of reaction }(-) \\ i: & \text { Incidence }\left(\text { deg }{ }^{\circ}\right) \\ \dot{m}: & \text { Mass flow rate }(\mathrm{kg} / \mathrm{s}) \\ n: & \text { Rotational velocity }(1 / \mathrm{s}) \\ \Delta t: & \text { Time difference }(\mathrm{s}) \\ t: & \text { Time }(\mathrm{s}) \\ P: & \text { Power }(\mathrm{W}) \\ T: & \text { Torque }(\mathrm{Nm}) \\ h: & \text { Enthalpy }(\mathrm{J} /(\mathrm{kg} \mathrm{K})) \\ s: & \text { Entropy }(\mathrm{J} /(\mathrm{kg} \mathrm{K})) . \\ & \end{array}$

\section{Abbreviations}

CFD: Computational fluid dynamics

MFP: Mass flow parameter

RFT: Radial flow turbine

MFT: Mixed flow turbine.
Greek Symbols

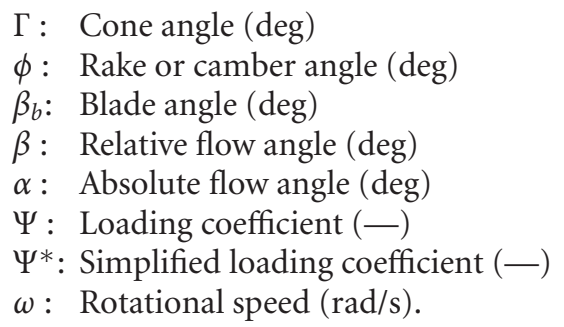

Indices

$\begin{array}{ll}\text { opt: } & \text { Optimum } \\ s: & \text { Static } \\ t: & \text { Total } \\ z: & \text { Axial, in } z \text {-direction } \\ r: & \text { Radial } \\ \text { is: } & \text { Isentropic } \\ \text { ss: } & \text { Static to static } \\ t t: & \text { Total to total } \\ \text { ts: } & \text { Total to static } \\ \text { 3: } & \text { Turbine stage inlet } \\ \text { 3.5: } & \text { Turbine wheel inlet } \\ \text { 4: } & \text { Turbine (wheel) exit } \\ m: & \text { Meridional } \\ T: & \text { Turbine } \\ \varphi: & \text { Circumferential } \\ \ddot{\varphi}: & \text { Acceleration. }\end{array}$

\section{References}

[1] D. Japikse and N. C. Baines, Introduction to Turbomachinery, Concepts ETI, 1997.

[2] R. Golloch, Downsizing bei Verbrennungsmotoren, Springer, 2005.

[3] P. Lückert, F. Kreitmann, N. Merdes et al., "The new 1. 8litre 4-cylinder petrol engine with direct injection and turbo charging for all passenger cars with standard drive trains from Mercedes-Benz," in Wiener Motorensymposium, 2009.

[4] D. Hagelstein, L. Hentschel, S. Strobel et al., Die Aufladeentwicklung für den Neuen 1.2l TSI Motor von Volkswagen, Aufladetechnische Konferenz, Dresden, Germany, 2009.

[5] F. Bäumel, J. Jedro, C. Weber, A. H. Hinkelmann, A. Mayer, and C. Kirschner, The Turbocharger of the Third Generation of the AUDI R4-TFSI Engines Using the Example of the New 1. 81 TFSI, Aufladetechnische Konferenz, Dresden, Germany, 2011.

[6] N. Merdes, C. Enderle, G. Vent, and R. Weller, "Der neue vierzylinder-ottomotor mit turbo-aufladung von MercedesBenz," Motortechnische Zeitschrift 12/2011, 72. Jahrgang, pp. 942-951, 2011.

[7] N. Watson and M. S. Janota, Turbocharging the Internal Combustion Engine, The MacMillan Press, 1982.

[8] J. Walkingshaw, S. Spence, J. Ehrhard, and D. Thornhill, "An investigation into improving off-design performance in a turbocharger turbine utilizing non-radial blading," in Proceedings of the ASME Turbo Expo Conference, 2011.

[9] N. C. Baines, "Fundamentals of turbocharging," Concepts NREC, Edward Brother Incorporated, 2005. 
[10] K. Zinner, Aufladung von Verbrennungsmotoren, Springer, Auflage, Germany, 1985.

[11] M. Abidat, H. Chen, N. C. Baines, and M. R. Firth, "Design of a highly loaded mixed flow turbine," Proceedings of the Institution of Mechanical Engineers Part A, vol. 206, no. 2, pp. 95-107, 1992.

[12] H. Chen and N. C. Baines, "The aerodynamic loading of radial and mixed-flow turbines," International Journal of Mechanical Sciences, vol. 36, no. 1, pp. 63-79, 1994.

[13] S. Rajoo and R. Martinez-Botas, "Mixed flow turbine research: a review," Journal of Turbomachinery, vol. 130, no. 4, Article ID 044001, 12 pages, 2008.

[14] D. Filsinger, G. Fitzky, and B. Phillipsen, "Flexible turbocharger turbine test rig MONA VI," in Proceedings of the 8th International Conference on Turbochargers and Turbocharging (IMechE'06), pp. 207-222, May 2006.

[15] B. Lüddecke, D. Filsinger, and M. Bargende, "On wide mapping of a mixed flow turbine with regard to compressor heat flows during turbocharger testing," in Proceedings of the 10th International Conference on Turbochargers and Turbocharging (IMechE'11), pp. 185-202, 2011.

[16] M. V. Casey and T. M. Fesich, "On the efficiency of compressors with diabatic flows," in Proceedings of the ASME Turbo Expo Conference, pp. 785-797, Orlando, Fla, USA, June 2009.

[17] Kistler Instrumente AG Winterthur, CH-8408 Winterthur, Switzerland, Pressure Sensors Type 4045 and 4075, http://www.kistler.com/mediaaccess/4045A10__000-064m-10 92.pdf.

[18] V. Smiljanovski, J. Scharf, N. Schorn, S. Pischinger, and B. Funken, Messung des Turbinen-Wirkungsgrads bei Niedrigen Drehzahlen, Aufladetechnische Konferenz, Dresden, Germany, 2008.

[19] S. Scharf, Extended turbocharger mapping and engine simulation [Dissertation], RWTH, Aachen, Germany, 2010.

[20] A. Pesiridis, W. S. I. W. Salim, and R. F. Martinez-Botas, "Turbocharger matching methodology for improved exhaust gas energy recovery," in Proceedings of the 10th International Conference on Turbochargers and Turbocharging (IMechE '12), pp. 203-218, 2012.

[21] N. Baines and C. Fredriksson, "The simulation of turbocharger performance for engine matching," Motorprozesssimulation und Aufladung, 2, pp. 101-111, 2007.

[22] N. Ikeya, H. Yamaguchi, K. Mitsubori, and N. Kondoh, "Development of advanced model of turbocharger for automotive engines," SAE Paper 920047, 1992.

[23] P. Scheller, C. Schnückel, C. Jördens, D. Hagelstein, and J. Theobald, Evaluation Study of Different Turbine Wheel Geometries for Turbocharged Gasoline Engines, Aufladetechnische Konferenz, Dresden, Germany, 2011. 

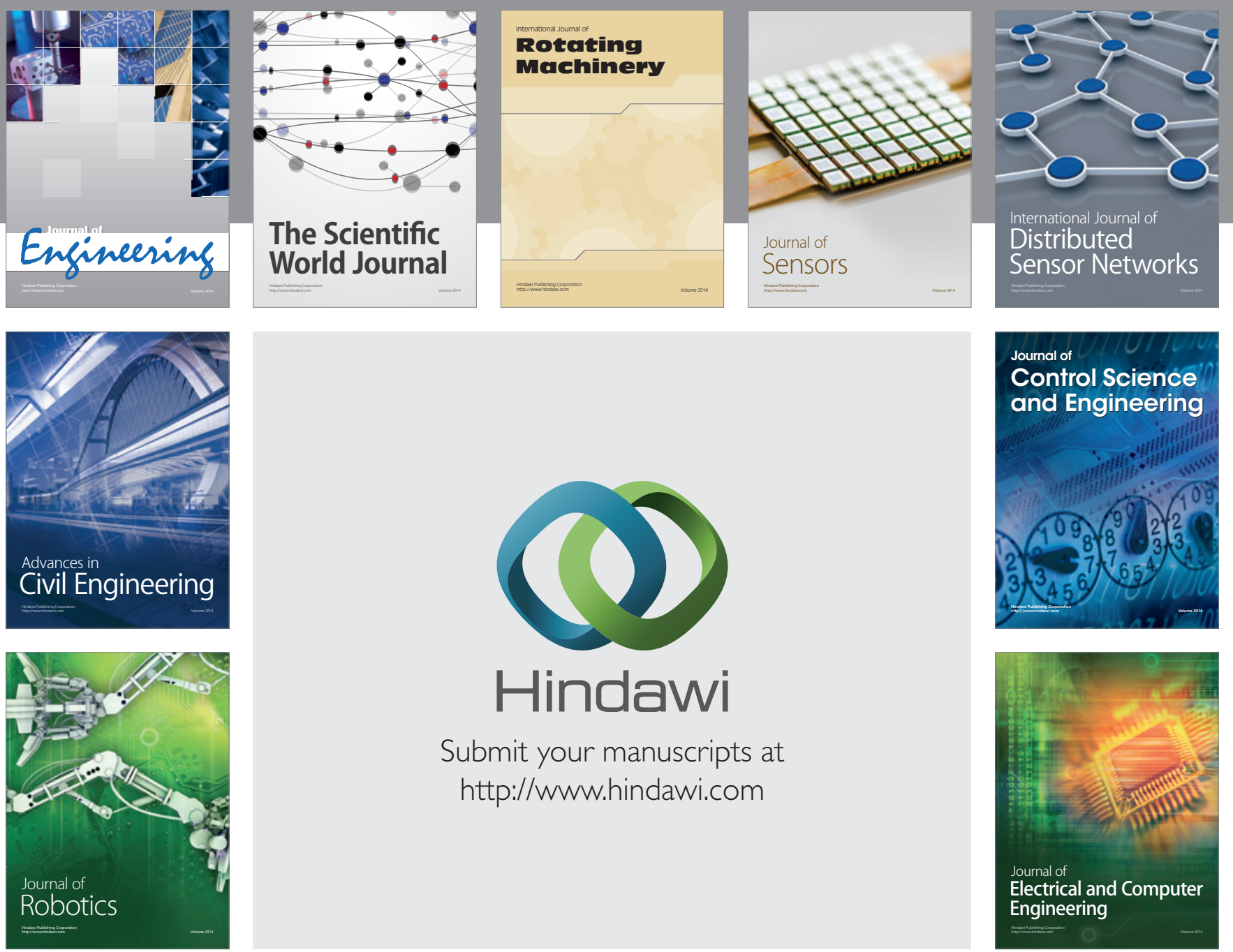

Submit your manuscripts at

http://www.hindawi.com
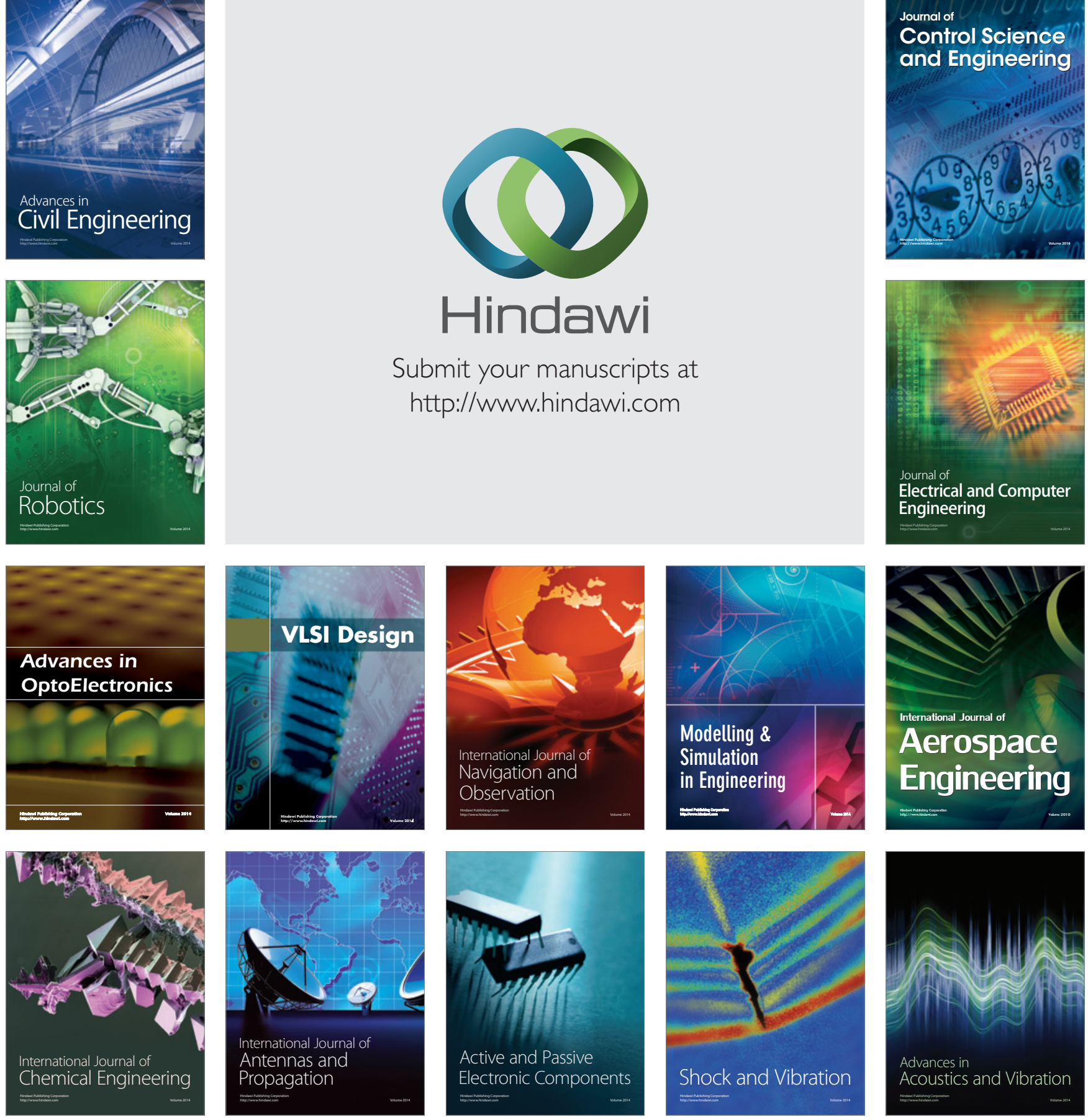